\title{
Magnitude and latency of the pupillary response during an imagery task as a function of stimulus abstractness and imagery ability
}

\begin{abstract}
ALLAN PAIVIO, DEPARTMENT OF PSYCHOLOGY, UNIVERSITY OF WESTERN ONTARIO, London, Canada AND HERB M. SIMPSON, DEPARTMENT OF PSYCHOLOGY, CARLETON UNIVERSITY, Ottawa, Canada

The Ss who differed in imagery ability according to scores on a test battery were asked to generate mental images suggested by concrete and abstract stimulus words. Pupillary reactions were continuously photographed during the task. The results showed no significant effects attributable to imagery ability. Imaging to words was associated with dilation and maximum dilation occurred sooner when the stimulus was concrete than when it was abstract, but pupil size was relatively unaffected by abstractness. The findings suggest that pupillary response latency may be more sensitive than magnitude as an indicator of cognitive-task difficulty.
\end{abstract}

Pupillary dilation typically occurs when a $S$ is engaged in mental activity, the magnitude of the reaction apparently varying with the difficulty of the cognitive task (e.g., Beatty \& Kahneman, 1966; Hess \& Polt, 1964). Such a reaction occurred when Ss attempted to generate mental images to stimulus words (Paivio \& Simpson, 1966; Simpson \& Paivio, 1966), the dilation being somewhat greater and reaching a maximum later when the words were abstract than when they were concrete, as expected from the hypothesis that imaging is more difficult in the case of abstract stimuli (cf. Paivio, 1966). The present experiment extended this line of research to include individual differences in imagery ability. Assuming that the observed effects are indeed a function of the difficulty of image arousal and that a measure of imagery ability is a valid indication of the S's ability to think in terms of nonverbal images, it would be expected that low imagery Ss would experience more difficulty and show more pupillary dilation during the task than would high imagers, particularly when the stimulus word is abstract. The effects should also be manifested in differential latencies to maximal pupil size.

Simpson \& Paivio (1968) have shown that the dilation during a cognitive task is enhanced when $S$ is required to make a response indicating task fulfilment. To avoid confounding the task oriented response and mental activity, no overt response was included in the present experiment.

Method

Subjects. The Ss were classified on visual imagery ability on the basis of a total score on an imagery test battery, which has been used and described in other research (e.g., Simpson, Paivio, \& Rogers, 1967). Four hundred and fifty Ss completed the test battery. Extreme cut-off scores of 35 and 18 yielded 27 and 29 Ss denoted "high" and "low" visual imagers, respectively. The number of Ss in each group was reduced to 18 , since Ss who required glasses to read or had dark irises were rejected.

Apparatus. The apparatus (see Paivio \& Simpson, 1966) consisted principally of a box-like compartment open at one end where $S$ was seated. The other end of the box contained a screen onto which the stimuli were projected. Photographs of S's right eye were taken by means of a $16 \mathrm{~mm}$ camera at a filming speed of two frames per second.

Stimulus material. The stimulus items were four abstract (low imagery) and four concrete (high imagery) nouns selected from a pool of items that have been scaled for concreteness and image-evoking value (Paivio, Yuille, \& Madigan, 1968). The concrete terms were coffee, house, pencil, and tree; the abstract terms were fate, moment, opinion, and virtue. Transparent photographic slides of the words constituted the stimuli. A "control" for each word was also prepared so that the amount of typewritten material on a word slide was closely matched to that on a control slide, namely, two " $x$ 's," each " $x$ " bounded above and below by a line. ${ }^{2}$ Two stimulus lists were constructed, each list containing the eight words, each word preceded by its corresponding control. The first list was determined by random assignment of the words with the restriction that no more than two words of a type (e.g., concrete) occurred in sequence. The second list was the reverse of the first.

Procedure. The Ss were tested individually. Instructions were presented by a tape recorder. The term "image" was defined and S was told that the task was to "...picture in your mind whatever the words that you will see make you think about." Each stimulus was projected for $10 \mathrm{sec}$ with a $2 \mathrm{sec}$ interstimulus interval. Equal numbers of $S s$ in each group received the first and second lists.

The processed movie film was examined frame by frame on a film editor and the magnified pupil diameter measured in $\mathrm{mm}$.

Results and Discussion

Pupil size. Pupil size for each photographic frame was summed across each word type (i.e., concrete or abstract) as well as for the respective control conditions separately for each $\mathrm{S}$. The data for the 20 photographic frames were collapsed into four equal time blocks and analyzed using a 2 by 2 by 2 by 4 analysis of variance with $S$ type (high vs low imager), stimulus conditions (word vs control slide), abstractness, and blocks as factors. The main effect of $S$ type was not significant $(F=0.10)$ nor were the interactions involving $\mathrm{S}$ type. Significant effects were obtained for stimulus conditions $(\mathrm{F}=5.60, \mathrm{df}=1 / 34, \mathrm{p}<.01)$, blocks $(\mathrm{F}=23.28, \mathrm{df}=$ $3 / 102, p<.01)$, and the interaction of blocks and stimulus conditions, $(\mathrm{F}=4.65$, $\mathrm{df}=1 / 102, \mathrm{p}<.01)$. The effect of abstractness was not significant $(F=0.88)$. The pupillary response curves are shown in Fig. 1 (with $S$ type collapsed) where it can be seen that dilation was greater to word than control slides, particularly in the second block of frames. These effects, including the direction of the nonsignificant effect of abstractness, are similar to those described by Simpson \& Paivio (1966).

Latency of dilation. The time interval from stimulus presentation to the photographic frame in which maximum pupillary diameter occurred to a word was summed over words for each $S$, separately for abstract and concrete stimuli. These data were analyzed using a 2 by 2 analysis of variance with $S$ type (high vs low imager) and word abstractness as variables. The effect of abstractness was significant $(F=9.47$, df $=1 / 34, \mathrm{p}<.01)$, maximum pupil size occurring sooner to the concrete than abstract words, as indicated by the arrows in Fig. 1. The effect of $S$ type again was not significant $(F=1.55)$, although the differences were in the appropriate direction, the latencies being longer for low imagery Ss.

The data are consistent with the results of previous research (Paivio \& Simpson, 1966; Simpson \& Paivio, 1966), which has shown that pupillary dilation is reliably associated with attempts to generate images to stimulus words. A significant effect of word abstractness was found in a previous study (Paivio \& Simpson, 1966) dilation being greater to abstract than concrete words. In that experiment, however, Ss pressed a telegraph key when they discovered an image, and subsequent studies (Simpson \& Paivio, $1966 ; 1968)$ indicated that removal of the key press reduced the effect of abstractness. Although the effect is attenuated when no key press is involved, differential dilation to abstract and concrete words has been consistently obtained even without the motor response (Simpson \& Paivio, 1966, as well as the present experiment) suggesting a small, but reliable effect. By contrast, the latency of pupillary dilation was significantly related to abstractness, which is consistent with data from previous experiments (e.g., Paivio \& Simpson, 1966) and suggests that the latency of dilation may be a more sensitive indicator of mental effort than is pupil size. That is, latency is differentially affected by stimulus 


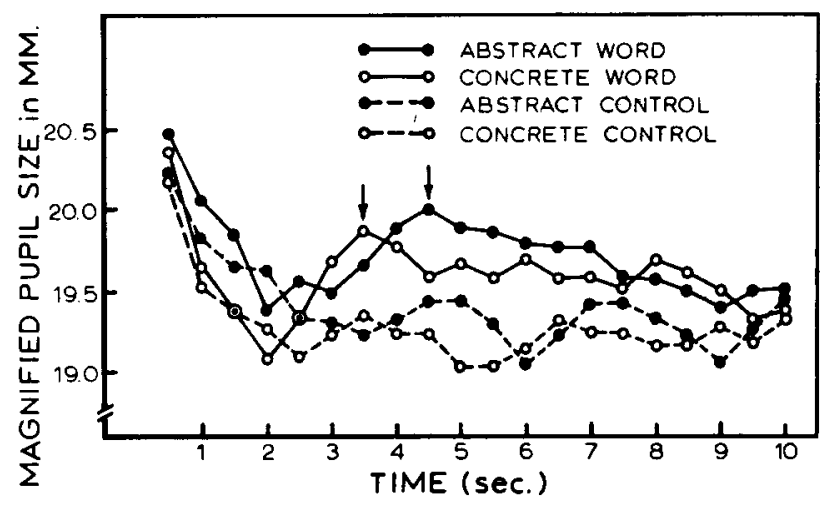

Fig. 1. Pupillary response curves as a function of stimulus conditions and abstractness. Arrows indicate points of maximal dilation.

concreteness even when no overt indicator of task fulfillment is involved, whereas pupil size is particularly affected by the overt response used to indicate task fulfillment. ${ }^{3}$

Finally, it is apparent that differences in imagery ability, as measured by the battery of tests we used, are not predictive of differential pupillary reactions in our experimental situations.

\section{REFERENCES}

BEATTY, J., \& KAHNEMAN, D. Pupillary changes in two memory tasks. Psychon. Sci., 1966, 5, 371-372.
HESS, E. H., \& POLT, J. M. Pupil size in relation to mental activity during problem-solving. Science, 1964, 143, 1190-1192.

PAIVIO, A. Latency of verbal associations and imagery to noun stimuli as a function of abstractness and generality. Canad. J. Psychol., 1966, 20, 378-387.

PAIVIO, A., \& SIMPSON, H. M. The effect of word abstractness and pleasantness on pupil size during an imagery task. Psychon. Sci, 1966, 5, 55-56.

PAIVIO, A., YUILLE, J. C., \& MADIGAN, S. A. Concreteness, imagery, and meaningfulness values for 925 nouns. J. exp. Psychol. Monogr. Suppl., 1968, 76, No. 1, Part 2.

SIMPSON, H. M., \& PAIVIO, A. Changes in pupil size during an imagery task without motor response involvement. Psychon. Sci. 1966, 5, 405-406.

SIMPSON, H. M., \& PAIVIO, A. Effects on pupil size of manual and verbal indicators of cognitive task fulfillment. Percept. \& Psychophys., 1968, 3, 185-190.

SIMPSON, H. M., PAIVIO, A., \& ROGERS, T. B. Occipital alpha activity of high and low visual imagers during problem solving. Psychon. Sci, 1967, 8, 49-59.

\section{NOTES}

1. This research was supported by grants APA-87 (to the first author) and APA-204 (to the second author) from the National Research Council of Canada as well as grants to both authors from the University of Western Ontario Research Fund.

2. Photometric readings from each of the projected slides indicated that the control and word slides were closely matched for brightness, the overall illumination being slightly greater for words than controls in all but one instance.

3. Simpson \& Paivio (1968) have recently discussed several variables that might account for the effect of the overt response. 